\title{
CONCURRENT SIMULATION AND OPTIMIZATION MODELS FOR MINING PLANNING
}

\author{
Marcelo Moretti Fioroni \\ Luiz Augusto G. Franzese \\ Paragon Tecnologia \\ 1435, Clodomiro Amazonas St, $5^{\text {th }}$ floor \\ São Paulo, SP, 04537-012, Brazil
}

\author{
Tales Jefferson Bianchi \\ Luiz Ezawa \\ VALE \\ Águas Claras Mine \\ Ligação Av, 3580 \\ Nova Lima, MG, 34000-000, Brazil
}

\author{
Luiz Ricardo Pinto \\ Gilberto de Miranda Jr.
}

Federal Universty of Minas Gerais

Presidente Antônio Carlos Av, 6627

B. Horizonte, MG, 30161-010, Brazil

\begin{abstract}
One of the most important challenges for mining engineers is to correctly analyze and generate short-term planning schedules, or simply month mining plan. The objective is to demonstrate how simulation and optimization models were combined, with simultaneous execution, in order to achieve a feasible, reliable and accurate solution for this problem. A tool based on Arena simulation software and Lingo was developed, tested and approved within VALE (former CVRD Brazil), with excellent results, presented in this paper.
\end{abstract}

\section{INTRODUCTION}

The main concern when building a simulation model is to assure that the model will correctly represent the real system. To achieve that, the analyst must consider a detail level just enough to reproduce the reality for the goals of the study. Procedures that exists on the system but do not affect the measurement of the desired results, should not be modeled, but relevant elements cannot be ignored.

Porto \& Lobão (1999) tells that when a model is built too detailed and complex, it becomes slower, hard to understand and to give maintenance. That facts decreases it's reliability, as seen on Figure 1.

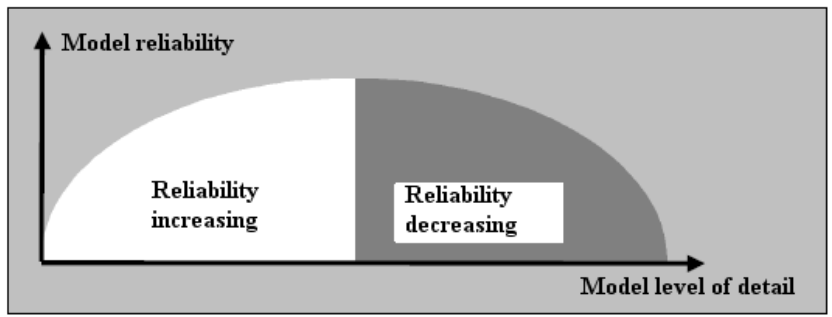

Figure 1: Reliability vs. Level of Detail

When modeling more complex systems, the analyst is not usually forced to model the exact procedure as it is done in the real system. Frequently the model version of the process can be simpler. Pidd (1998) tells that the model must not have the same complexity of the real process, because it is part of a "user-model" system. Pidd states: "model simple, think complicated".

But sometimes, there is no way to avoid or simplify a complex procedure without loses precision on the results. Sometimes the system has procedures involving decisions or other critical elements that are very important for the system behavior.

This paper presents a case where the real system has an optimization procedure that is periodically executed to achieve quality and production goals. Without that procedure, the model results would be completely different than the real system.

The representation of an optimized procedure in a model is a real obstacle for the model builder, because discrete event simulation tools are not designed to solve complex optimization problems in a fast, easy way. The use of optimization model associated with a simulation model can be used to solve these types of problem (Merschmann 2002).

The objective is to provide to the mine feasible goals for quality and quantity production of ROM (Run of Mine). This is critical, because a goal lower than possible represents profit loose for the company and a goal higher than possible have many serious consequences, since the mine managers are evaluated based on the accomplishment of that goals.

\section{MINING MONTHLY PLAN PROBLEM}

The stage of mining planning is very important in any type of mineral mining, because it seeks cost reduction while maximize mass production plans, while focusing in quality and operation requirements, as well as asset utilization and restraints such as shovels, trucks, tractors, etc.

In this way "Planning" means "Predictability", since it is necessary to verify if a plan can be executed or not, in agreement with the available resources and has the smallest possible cost. 
In a surface mine, ROM is extracted from different mining areas. Each mining area have a truck loader to load ROM. Material is then carried to a main pile or to a primary crusher, that receives material from all mining areas.

Main problem is to keep ROM grade quality in that pile, meaning to assure the correct grade of iron ore and other important parameters. Each mining area has a different grade of iron ore, so mine manager must extract the correct quantity of material on each area to reach the desired quality (grades) and quantity at the main ROM pile.

This means to allocate the truck fleet to all mining areas and make the correct number of trips at each one, as can be seen at Figure 2. Plus, some mining areas require the waste material to be removed before reaching the ore. So truck fleet must be allocated to work on these areas too.

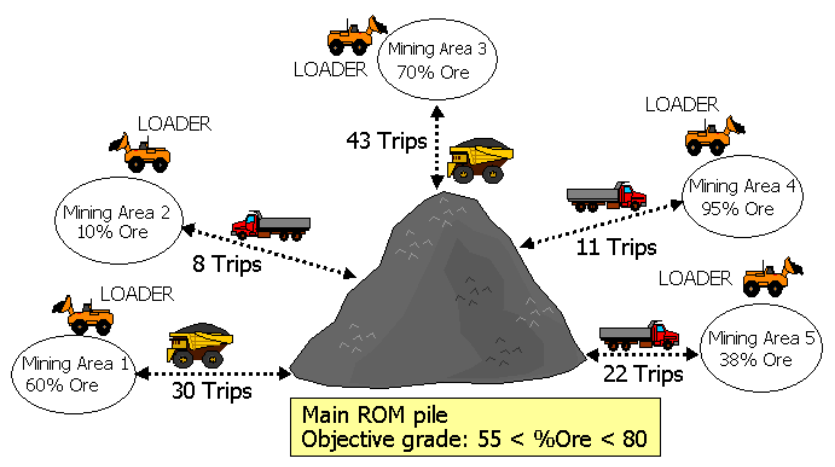

Figure 2: Formation of the ROM main pile

This problem could be modeled using a regular optimization tool, focused at truck allocation and calculate truck fleet assigned to correct areas, estimating number of trips at each one to reach the desired ore grade at ROM pile. The truck/shovel allocation problem in mines is a Multiple Integer Knapsack Problem and it is NP-hard optimization problem (Costa et al. 2004, 2005). This problem and its variations had already been studied by several authors as Alarie and Gamachie (2002) Costa et al. (2004), 2005, White and Olson, 1986 and many others. But the real process has many other variables, some of them stochastic, that impact on the plan, such as:

- $\quad$ Loader maintenance;

- Truck maintenance;

- Exhaustion of ore at the mining area (at the ore removing areas);

- Exhaustion of waste at the mining area (at the waste removing areas);

- Averages do not reflect precisely truck operations loading and transportation variation.

A discrete-event simulation model is able to reproduce the randomness of the equipment problems and the time variation of the trips and processes. This makes simulation a good tool to check the feasibility of the plan. According to Rasche and Sturgul (1991) simulation models are used in mine industry since 1961. Furthermore, simulation has become an important tool in order to monitor mine operations (Turner 1999) and to analyze complex mine systems (Panagiotou 1999). But a simulation model itself is not able to precisely represent through heuristics some complex decisions logic that are used to choose the best the trip plan at each process interference. Then it is absolutely necessary planning the number of trips using the optimization model.

However, the use of optimization model as a procedure of simulation model allows a more realistic simulation. At the beginning of the simulation, the optimization model is run in order to calculate the initial shovel allocation and the schedule truck trips. After that, the simulation model is run until a system state change (failure in any equipments or lack of material in any mining area). The simulation model calls the optimizer procedure to calculate the new optimization and so on.

The proposed solution is the integration of both tools: discrete-event simulation and optimization, not as a post or pre-simulation run, but as a combined run.

\section{SIMULATION WITH OPTIMIZATION}

An optimization tool is traditionally used to find the best way to execute some task. But in this case, it will help the simulation model to have the correct similarity with the real system.

A simulation model can reproduce the system behavior and its randomness while executing the truck trip plan, generating maintenance events based on the real mine historic data, and other interference events. Each interference event must call the optimization tool, that recreates the plan and communicate it to the simulation model. Figure 3 illustrates this process.

\section{Simulation timeline}

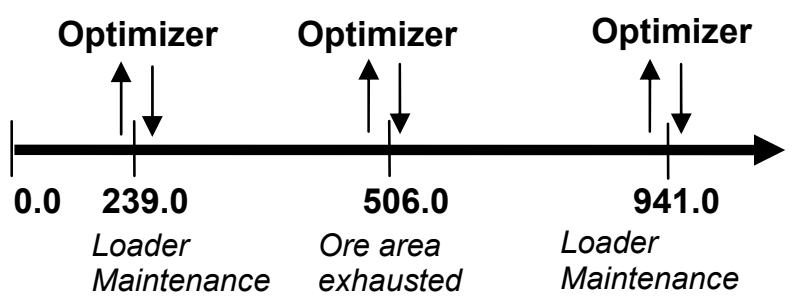

Figure 3: Simulation with Optimization

The number of interactions between simulation and optimization depends of the mining areas number and their qualities and total mass; it also depends of the shovels and trucks fleet availability. For all simulated cases, the minimum interactions are: 
- Once per day, where the optimizer try to control or to correct qualities problems. Normally the period simulated is one month or 31 days;

- For each event of mining area exhausted. When a mining area is exhausted the loader needs to be allocated in other area.

- For each maintenance events for shovels and trucks that can implicate in an inadequate blending. For example, if one loader allocated in a mining area with good quality broken down, probably the total blending will present problems. The interaction occurs to correct this problem.

For each interaction the optimization model tries to keep the same previous scenario to minimize the movement of shovels on the mine. It is absolutely necessary to be sure that the equipment allocation and trips number will allow a production with quality control.

The two models (simulation and optimization) stop to run when the replication time (one month) finishes, that mean the mining plan is satisfactory or when there is no more blending possibilities to reach the quality results. In this case the mining plan is not good enough to be mined with quality up to the end of replication.

\subsection{Models Design}

The challenge in this phase was develop a tool to optimize the equipments allocations, which will work together with the mining simulation system.

Optimization model will run every time that the simulator program begin, with the objective of execute the initial allocation of the loader and transport equipments whose operations will be simulated. This program will also run during the simulation, when an event such as load equipment and/or a transport failure happen, seeking new optimal equipment allocation, as well as distribution of the remaining trucks.

The program will route load equipment to correct mining areas and will determinate the amount of trips that each truck should take to each area, in order to achieve production and quality goals defined.

\subsection{Discrete Event Simulation Model}

The simulation model was developed in the ARENA software, and helps identify how many trips each truck should perform in each area, so that the grade ore will reach in the simulation period. VBA was used for communication between simulator and optimizer.

\subsubsection{Objectives}

The objective of this simulation model is to allow the viability of the mining plan proposed by optimizer, presenting utilization and production. This evaluation also includes equipment breakdown and re-planning or extraction in several areas.

\subsubsection{Simulation Model Limits}

The system was developed to represent all the important aspects of a mining operation, with the following limits:

- 40 mining areas;

- 40 transporter equipments (trucks);

- 15 loader equipments;

- 1 waste pile;

- 1 crusher.

\subsubsection{Animation}

Animation was used to validate transportation procedures, as well as present results to top management. Among several animation screens, a complete mine view can be seen on Figure 4.

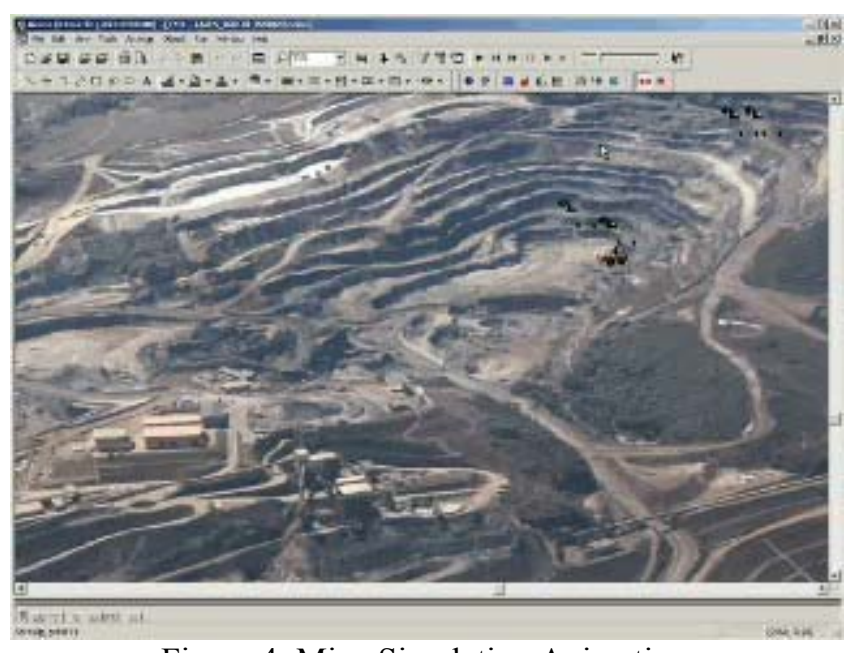

Figure 4: Mine Simulation Animation

\subsection{Optimization}

\subsubsection{Objectives}

The objective of this optimization model is to run each time that the simulator program begin, to produce initial allocation of the loader and transportation equipment.

This model will also run during the simulation, when equipment and/or a truck failure may happen, seeking a 
new optimal allocation for shovel and remaining trucks. It will also generate shovels allocation to different mining areas and will calculate amount of trips that each truck should take to each area, to reach production goal.

\subsubsection{Optimization Model Parameters}

Optimization model main data include:

- Minimum and maximum capacity of each load equipment;

- Trucks capacity;

- Total production to be reached;

- $\quad$ Range of desired grades for each control variable (minimum and maximum grade of Run of Mine);

- Grades for each control variables to each mining area;

- Weight of each control variables;

There is an open pit mine working with system shovels and trucks, where there was a grade control of several involved variables. This job considered the grade control of chemical variables in each grand-size partition of the areas (pellet feed, sinter feed and lump ore).

For each short-term mining plan elaborated, there are $n$ available areas, where the mine can be operated simultaneously in $m(m \leq n)$ of those areas, depending of the shovels available.

If these equipment start to operate, due to technical and economical reasons, each loader equipment shall work between production limits previously defined.

Each truck should assist only mining area and, an area can have more than one truck allocated.

\subsubsection{Features and limitations of the optimizer}

The optimizer can be used to do all system planning, indicating the trucks/shovels allocation, with the respective trucks trips plan calculation or simply to do trucks allocation and its trips planning.

The optimizer will have the following constraints:

- 30 mining areas;

- 80 transport equipments (trucks);

- 15 shovels;

- 2 unload point (1 for ore and 1 for waste);

- 6 control variables in 3 size fractions.

\subsubsection{Optimization Model}

This model was partially transcribed by Pinto and Merschmann (2001) and Costa et al (2004, 2005), and current version contains different trucks and loader equipment. Optimization model is detailed below:
Sets:

$I=$ mining areas;

$V=$ chemical variables;

$J=$ loading equipments;

$K=$ types of trucks;

Subsets:

$I^{o} \subseteq I=$ ore areas;

$I^{w} \subseteq I=$ waste areas;

$J^{o} \subseteq J=$ shovels that operate only at ore areas;

$J^{w} \subseteq J=$ shovels that operate only at waste areas.

Parameters:

$F_{k}=$ quantity of trucks of type $k$;

$t_{v i}=$ grade of variable $v$ in the area $i(\%)$;

$L B_{v}=$ lower bound to variable $v(\%)$;

$U B_{v}=$ upper bound to variable $v(\%)$;

$w_{v}=$ weight of variable $v$ (indicates the relative importance of variable $v$ );

$g_{i v}=\%$ partition value for variable $v$ at area $i$

$y_{j k} \in\langle 0,1\rangle=$ compatibility of loader $j$ and truck $k$ (if

$y_{j k}=1$ then loader $j$ can operate with truck type $k$ and

$y_{j k}=0$, otherwise);

$a_{i} \in\langle 0,1\rangle=$ area availability $(1=$ available and $0=$ not available);

$a t v_{i} \in\langle 0,1\rangle=$ type of material at the area $\mathrm{i}(1=$ ore and 0 = waste);

$P \max _{j}=$ maximum production possible for the loader $j$ (ton/h);

$P \min _{j}=$ minimum production possible for the loader $j$ (ton/h);

$Q^{o}{ }_{i}=$ maximum amount of ore at the area $i$ (tones);

$Q^{w}{ }_{i}=$ maximum amount of waste at the area $i$ (tones);

eqe $e_{j} \in\langle 0,1\rangle=$ type of material in which the loader $j$ can operate $(1=$ ore and $0=$ waste $)$;

$d_{j} \in\langle 0,1\rangle=$ loader availability $(1=$ available and $0=$ not available);

$S R R=$ minimum strip ratio required (ton/ton);

$M C_{i j}=$ cost to move loader $j$ to area $i$ (tones);

$P_{\text {req }}=$ minimum ore production required (tones);

$T=$ duration of the planning (hours); 
$M=$ mass of the current ore batch (tones);

$t b_{v}=$ grade of variable $\mathrm{v}$ at current ore batch $(\%)$;

$t c_{k i}=$ cycle time for area $i$ using truck type $k$ (seconds);

$N_{k i}=$ maximum possible trips of truck type $k$ at area $i$;

$c_{k}^{o}=$ working load of truck type $k$ for ore (tones);

$c_{k}^{w}=$ working load of truck type $k$ for waste (tones);

Decision variables:

$P_{i} \in R=$ Production of area $i$ (tones);

$x_{i j} \in\langle 0,1\rangle=$ assignment of loader $j$ to area $i$;

$n_{k i} \in Z=$ trips of truck type $k$ to area $i$;

$e_{v}^{+}=$positive deviation for variable $v(\%)$;

$e_{v}^{-}=$negative deviation for variable $v(\%)$;

Objective function:

$\operatorname{Max} Q=\sum_{i} a t v_{i} P_{i}-\sum_{v} w_{v}\left[e_{v}^{+}+e_{v}^{-}\right]-\sum_{i \in I} \sum_{j \in J} M C_{i j} x_{i j}$

Subject to:

A - Allocation Constraints:

$$
\begin{array}{cc}
\sum_{j \in J} x_{i j} \leq 1 & \forall i \in I \\
\sum_{j \in J^{o}} x_{i j}=0 & \forall i \in I^{w} \\
\sum_{j \in J^{w}} x_{i j}=0 & \forall i \in I^{o} \\
\sum_{i \in I^{w}} x_{i j} \leq d_{j} & \forall j \in J \\
n_{k i} \leq \sum_{j \in J}\left[F_{k} \times N_{k i} \times y_{j k} \times a_{i}\right] \times x_{i j} \forall k \in K, \forall i \in I \\
\sum_{i \in I} t c_{k i} \times n_{k i} \leq 3600 \times F_{k} \times T & \forall k \in K
\end{array}
$$

B - Production Constraints:

$$
P_{i} \leq \sum_{j \in J} T \times P \max _{j} \times x_{i j} \quad \forall i \in I
$$

$$
\begin{array}{r}
P_{i} \geq \sum_{j \in J} T \times P \min _{j} \times x_{i j} \quad \forall i \in I \quad(8) \\
\sum_{i \in I^{o}} P_{i} \geq P_{r e q}(9) \\
a t v_{i} \times P_{i} \leq Q^{o}{ }_{i} \quad \\
\left(1-a t v_{i}\right) \times P_{i} \leq Q^{w}{ }_{i} \quad \forall i \in I \quad(10)
\end{array}
$$$$
P_{i}=\sum_{k \in K}\left(a t v_{i} \times c_{k}^{o}+\left(1-a t v_{i}\right) \times c_{k}^{w}\right) \times n_{k i} \forall i \in I
$$$$
\sum_{i \in I}\left[\left(1-a t v_{i}\right) \times P_{i}\right]-S R R \sum_{i \in I}\left[a t v_{i} \times P_{i}\right] \geq 0
$$

C - Quality Constraints:

$$
\begin{gathered}
\sum_{i \in I}\left[t_{v i} \times a t v_{i} \times P_{i} \times g_{v i}\right]+t b_{v} \times M- \\
-e_{v}^{+} \leq U B_{v}\left[M+\sum_{i \in I}\left(a t v_{i} \times P_{i} \times g_{v i}\right)\right] \forall v \in V \\
\sum_{i \in I}\left[t_{v i} \times a t v_{i} \times P_{i} \times g_{v i}\right]+t b_{v} \times M+ \\
+e_{v}^{+} \geq L B_{v}\left[M+\sum_{i \in I}\left(a t v_{i} \times P_{i} \times g_{v i}\right)\right] \forall v \in V
\end{gathered}
$$

The meaning of each constraint is:

(1) each loader should be in an only area;

(2) shovels that operate only in ore area can not operate in waste area;

(3) shovels that operate only in waste area can not operate in ore area;

(4) only availability shovels can be used;

(5) the number of trips should be smaller than the largest number of trips allowed for the fleet of trucks in that area;

(6) the number of trips for fleet of trucks should be smaller than the allowed maximum;

(7) the production of the area should be smaller than the loader's maximum production allocated for the area;

(8) the production of the area should be greater than the loader's minimum production allocated for the area;

(9) the total production of ore should be larger or equal the requested minimum production;

(10) and (11) production of each area should be smaller or equal the maximum amount of existent material; 
(12) the production of each area should be same to the number of truck trips multiplied by your capacities;

(13) the minimum strip ratio should be guaranteed;

(14) and (15) the upper and lower bounds for each variable should be guaranteed;

\section{CASE STUDY}

Vale is the world's second-largest mining and metal company in market value, with assets of more than US\$ 100 billion. It is the world leader in production and export of iron ore and pellets and an important producer of nickel, copper concentrate, bauxite, alumina, potassium, kaolin, manganese and iron alloys.

Vale is also the biggest logistics service provider in Brazil, developing complete solutions by interlinking railways, ports and its own sea terminals.

Models were applied and approved at Vale's Aguas Claras Mines complex and currently are used for planning purposes.

In this case the numbers of elements in each set are:

$I=\mathbf{2 6}$ mining areas:

$V=\mathbf{9}$ chemical variables;

$J=\mathbf{9}$ loading equipments;

$K=\mathbf{2}$ types of trucks;

$I^{o} \subseteq I=\mathbf{1 2}$ ore areas;

$I^{w} \subseteq I=14$ waste areas;

$J^{o} \subseteq J=\mathbf{6}$ shovels that operate only at ore areas;

$J^{w} \subseteq J=\mathbf{3}$ shovels that operate only at waste areas.

These data results in a model with 330 decision variables and 265 constraints.

\section{QUANTITATIVE RESULTS}

Models can produce quantitative and qualitative results for any given scenario. For validation purposes a typical monthly plan was used and their results are presented below.

Mass of ore and waste mined for origin and destination (see Table 1).

Number of trips, by origin and destination, for calculation of average distance of transport (see Table 2) and quantification of transport costs (see Table 3).

Quantification of load costs starting from the ore and waste mass by load equipment and loaded in different types of transport (see Table 4).
Table 1: Simulated Production in tones, by area.

\begin{tabular}{|c|c|c|}
\hline & ZC Zone & ZE Zone \\
\hline Ore & 393978 & 366478 \\
\hline$\%$ & $34.4 \%$ & $32.0 \%$ \\
\hline waste & 846592 & 212290 \\
\hline$\%$ & $54.3 \%$ & $13.6 \%$ \\
\hline Strip Ration & 2.15 & 0.58 \\
\hline TOTAL & $45.9 \%$ & $21.4 \%$ \\
\hline
\end{tabular}

Table 2: Average distance of transport simulated, in $\mathrm{Km}$.

\begin{tabular}{|l|r|c|}
\hline Equipments & Ore & Waste \\
\hline Dresser & 1.01 & 1.66 \\
\hline Scania & 1.66 & 2.26 \\
\hline
\end{tabular}

Table 3: Transport costs simulated in $\mathrm{R} \$$.

\begin{tabular}{|l|l|l|}
\hline Equipments & Ore & Waste \\
\hline Dresser & $\mathrm{R} \$ 101835$ & $\mathrm{R} \$ 698466$ \\
\hline Scania & $\mathrm{R} \$ 689385$ & $\mathrm{R} \$ 373676$ \\
\hline $\mathrm{R} \$$ (Total) & $\mathrm{R} \$ 791220$ & $\mathrm{R} \$ 1072142$ \\
\hline
\end{tabular}

Table 4: Simulated load cost in R \$.

\begin{tabular}{|l|l|l|l|}
\cline { 3 - 4 } \multicolumn{2}{c|}{} & \multicolumn{1}{c|}{ Ore } & \multicolumn{1}{c|}{ Waste } \\
\hline \multirow{5}{*}{ Equipments } & \multicolumn{1}{c|}{$\begin{array}{c}\text { Load } \\
(\mathrm{R} \$)\end{array}$} & \multicolumn{1}{c|}{$\begin{array}{c}\text { Load } \\
(\mathrm{R} \$)\end{array}$} \\
\hline \multirow{4}{*}{ Dresser } & $\mathrm{P} \& H$ 2100 & $\mathrm{R} \$ 16244$ & $\mathrm{R} \$ 273105$ \\
\cline { 2 - 4 } & $\mathrm{P} \& H 1900$ & $\mathrm{R} \$ 0$ & $\mathrm{R} \$ 0$ \\
\cline { 2 - 4 } & $\mathrm{L} 1100$ & $\mathrm{R} \$ 24385$ & $\mathrm{R} \$ 310538$ \\
\cline { 2 - 4 } & $\mathrm{R} 964 \mathrm{G}$ & $\mathrm{R} \$ 24545$ & $\mathrm{R} \$ 10914$ \\
\cline { 2 - 4 } & $980 \mathrm{G}$ & $\mathrm{R} \$ 3254$ & $\mathrm{R} \$ 2036$ \\
\hline \multirow{3}{*}{ Scania } & $\mathrm{R} 964 \mathrm{G}$ & $\mathrm{R} \$ 271844$ & $\mathrm{R} \$ 137619$ \\
\cline { 2 - 4 } & $980 \mathrm{G}$ & $\mathrm{R} \$ 29634$ & $\mathrm{R} \$ 17180$ \\
\hline R\$ (Total) & & $\mathrm{R} \$ 36905.84$ & $\mathrm{R} \$ 751392.49$ \\
\hline
\end{tabular}

Quantification of ore and waste mass mined by loading equipment (see Table 5): 
Table 5: Simulated Production in tones, by loader.

\begin{tabular}{|c|c|c|}
\hline Equipment & Ore & Waste \\
\hline a964 & \multirow{5}{*}{1097736} & \multirow{5}{*}{550124} \\
\hline b964 & & \\
\hline c964 & & \\
\hline d964 & & \\
\hline e964 & & \\
\hline 980 & 73085 & 36954 \\
\hline $\mathrm{aP \& H} 2100$ & \multirow{2}{*}{47776} & \multirow{2}{*}{738122} \\
\hline bP\&H2100 & & \\
\hline aL1100 & \multirow{2}{*}{22372} & \multirow{2}{*}{345042} \\
\hline bL1100 & & \\
\hline Total & 1240968 & 1670242 \\
\hline
\end{tabular}

Quantification of ore and waste mass hauled by transport equipment (see Table 6):

Table 6: Simulated Production in tones, by truck.

\begin{tabular}{|l|c|c|}
\hline Scania & 1071347 & 542641 \\
\hline Dresser & 166284 & 1127128 \\
\hline Total & 1237630 & 1669770 \\
\hline
\end{tabular}

Qualitative analysis is also possible since grade and Phosphorus variable is also recorded.

\section{SCENARIO ANALYSIS}

A scenario was generated to compare a monthly plan with and without quality/grade constraints. Optimization model sensitivity was tested against the amount of ore production. The results demonstrate that production decrease while quality variability increases (see Figure $5 \&$ Figure 6). It can be explained due to successive loader changes (from each mining area) to try to keep quality control.

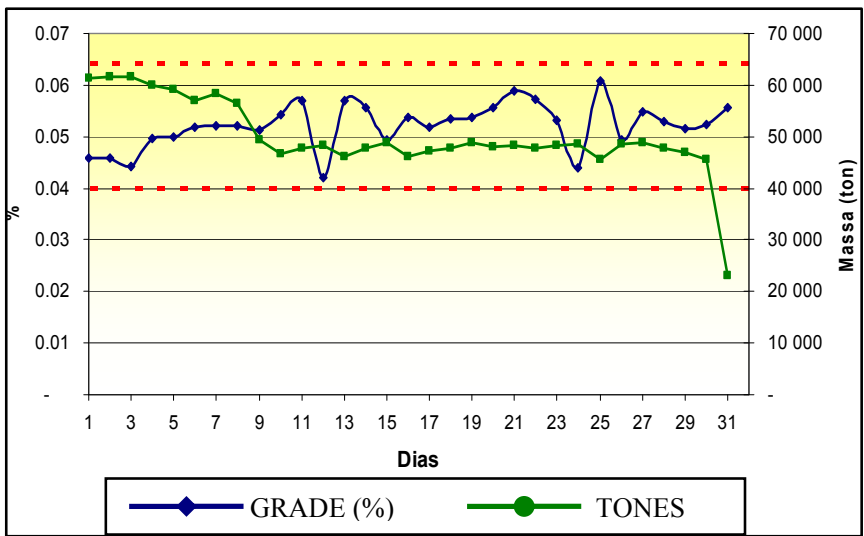

Figure 5: Phosphorus quality variation - WITH constraints.

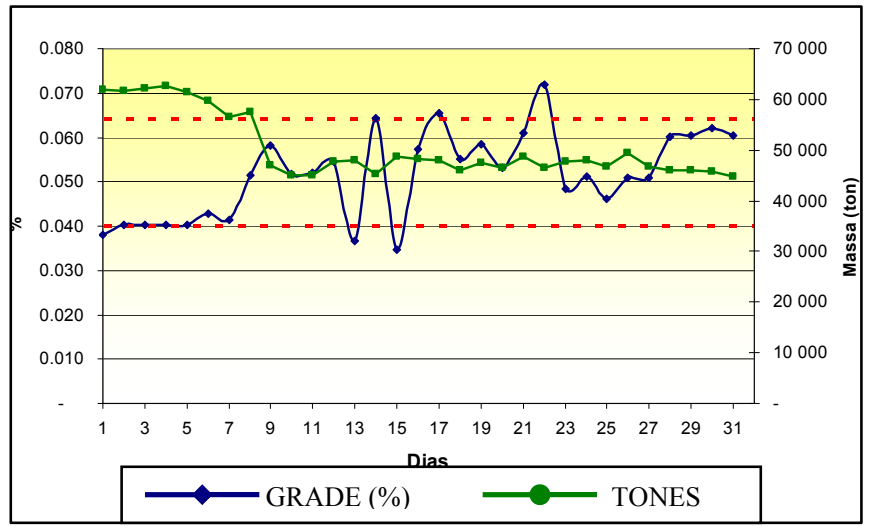

Figure 6: Phosphorus quality variation - WITHOUT constraints.

It is possible to establish the optimal number of layers during the formation of the homogenization pile, through arrival order of trucks on the crusher.

This mining site works with chevron-stacked pile, of 170.000 tones and $150 \mathrm{~m}$ length. Number of layers depends of the speed, where, high speed generates more layers.

Figure 7 presents $\mathrm{SiO}_{2}$ standard deviation (very important control parameter) according to the number of layers and truck arrival order. It is possible to conclude that the ideal layers amount is around 60 .

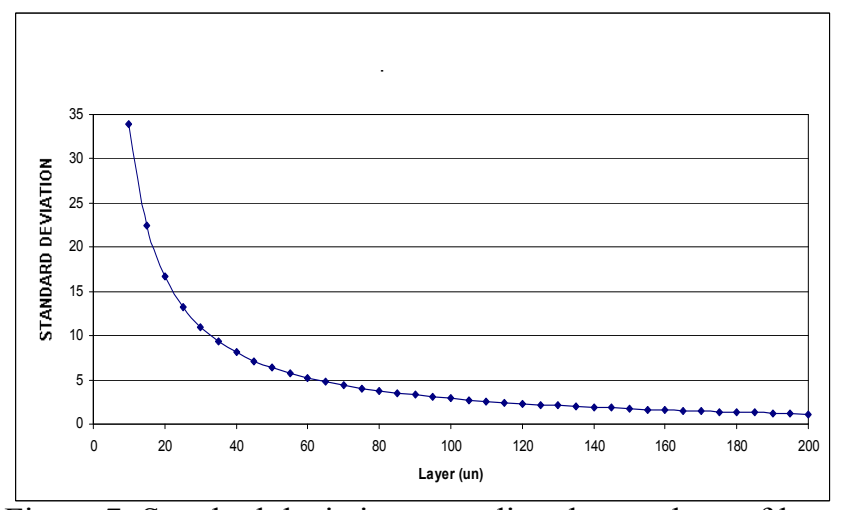

Figure 7: Standard deviation according the numbers of layers and arrival order of trucks.

\section{CONCLUSIONS}

Main objective was achieved, that was to reduce mining costs, through simulation and optimization usage in mining planning.

Presented solution also supplied comfortable and trustworthy results for mass and transportation distances, as well as quality measures and others intangible profits. 


\subsection{Profits of cost reduction}

During testing period, simulation model was responsible for a cost reduction of 4.97\%, when comparing FY 2005 with FY 2006. Cost was reduced from $1.33 \mathrm{R} \$ /$ Ton to 1.27 $\mathrm{R} \$$ /Ton, in 2006. That represents a comparative savings of 7.7 million Reais per year (4 million dollars).

\subsection{Intangible Profits}

As intangible profits for this project, recognized by VALE management team, some can be mentioned as:

- It supplied a tool for daily decision making within mining environment;

- It allowed the discussion of the mine plan prior to execution;

- It increased significantly the trustworthiness of mine plans to plant managers;

- It allowed equipment utilization analysis such as simulation versus reality;

- It made possible analyses several scenarios in small time interval.

\section{ACKNOWLEDGMENTS}

The authors thank VALE by supporting this project and for authorizing the use of its information.

\section{REFERENCES}

Costa, F. P., M. J. F.Souza, L. R. Pinto. 2004. Um modelo de programação dinâmica de caminhões. Revista Brasil Mineral,231: 26-31. (in portuguese)

Costa, F. P., M. J. F.Souza, L. R. Pinto. 2005. Um modelo de programação matemática para alocação estática de caminhões visando ao atendimento de metas de produção e qualidade. Revista da Escola de Minas, 58(1): 77-81. (in portuguese)

Gamache, M., and S. Alarie, S. 2002. Overview of solution strategies used in truck dispatching systems for open pit mines. International Journal of Surface Mining, Reclamation and Environment. 16(1): 59-76.

Merschmann, L. H. C. 2002. Desenvolvimento de um sistema de otimização e simulação para análise de cenários de produção em minas a céu aberto. Master Thesis, COPPE/UFRJ, Rio de Janeiro, Brazil. (in portuguese)

Panagiotou, G. N. 1999. Discrete mining system simulation in Europe. International Journal of Surface Mining, Reclamation and Environment 13: 43-46.

Pidd, M. 2003. Tools for thinking: modelling in management science, $2^{\text {nd }}$ Edition, John Wiley \& Sons Ltd, Chichester, England.

Pinto, L. R. , L. H. C. Merschmann. 2001. Planejamento operacional da lavra de minas usando modelos matemáticos. Revista Escola de Minas 54(3): 211-214. (in portuguese)

Porto, A. J. V., E. Lobão. 1999. Proposta para sistematização de estudos de simulação . Revista Engenharia Arquitetura, EESC-USP, 1(2): 61-69. (in portuguese)

Rasche, T., and J. R. Sturgul. 1991. A simulation to assist a small mine: a case study. International Journal of Surface Mining, Reclamation and Environment 5: 123-128.

Turner, R. J. 1999. Simulation in the mining industry of South Africa. International Journal of Surface Mining, Reclamation and Environment 13: 47-56.

White, J. P., and J. W. Olson. 1986. Computer-based dispatching in mines with concurrent operating objectives. Mining Engineering 38(11): 1045-1054.

\section{AUTHOR BIOGRAPHIES}

MARCELO MORETTI FIORONI is a simulation consultant with an Electrical Engineering degree, MSc. in Manufacturing and $\mathrm{PhD}$ in Logistics at University of São Paulo (USP). Has participated in almost 150 successful projects with simulation. Co-founder of PARAGON Tecnologia in 1992, the pioneer and leading consulting company in simulation in South America. Teaches Simulation at Faculdades Metropolitanas Unidas (FMU) in São Paulo, Brazil. Has trained more than 1,200 professionals in simulation. He can be contacted by email at <marcelo@paragon. com.br>

LUIZ AUGUSTO G. FRANZESE is a simulation consultant with a Production Engineering and MSc. in Logistics background, who has completed almost 150 successful projects with simulation. Founded PARAGON Tecnologia in 1992, the pioneer and leading consulting company in simulation in South America. Has trained more than 1,200 professionals in simulation. He can be contacted by email <augusto@paragon. com.br>

TALES JEFFERSON BIANCHI is Short Term Planning Engineer of Southern Ferrous Minerals Department (DIFL) of VALE. He holds the degrees of Mining Engineer from Federal University of Minas Gerais (UFMG) and Post Graduating in Open Cast Mining and Quarrying at École des Mines de Paris - France. He was consultant by Datamine Latin American with mining software for 4 years and now works with production engineering and development of technologies for open pit mines of VALE. Nowadays, he is studying. He can be contacted by email at <tales.bianchi@vale.com>

LUIZ EZAWA is Short Term Planning Manager of Southern Ferrous Minerals Department (DIFL) of VALE. He holds the degrees of Mining Engineer from Federal 
University of Ouro Preto (UFOP) and specialization in Engineering/Operational Research (COPPE/UFRJ). He has worked in several projects of simulation and optimization including the simulation ships shipment and development of a commercial software of mining optimization and dispatch system (TECMINE). He can be contacted by email at <ezawa.luiz@vale.com>

LUIZ RICARDO PINTO Phd in Production Engineering /Operational Research (COPPE/UFRJ - 1999) MSc. in Engineering (UFOP - 1988) Mining Engineer (UFOP - 1983) Professor at DEP/UFMG. He has worked as consultant in several projects concerning about operations research applied to mining industries and others. He is a professor of undergraduate and graduate course of Industrial Engineering at Federal University of Minas Gerais - UFMG. He can be contacted by email at <luiz@dep.ufmg.br>

GILBERTO DE MIRANDA JR. Phd in Computer Science (UFMG - 2004). Mechanical Engineer (UFMG 1995). Professor at DEP/UFMG. He is a professor of undergraduate and graduate course of Industrial Engineering at Federal University of Minas Gerais - UFMG. He can be contacted by email at <miranda@dep.ufmg.br>. 